\title{
Safety Effects of Geometric Design Consistency on Two-lane Rural Highways: The Case of Ethiopia
}

\author{
Shiferaw Megersa Gemechu, Getu Segni Tulu* \\ School of Civil and Environmental Engineering, Addis Ababa University, Addis Ababa, Ethiopia \\ Email address: \\ getu.segni@aait.edu.et (G. S. Tulu), megersa.shiferaw@yahoo.com (S. M. Gemechu) \\ ${ }^{*}$ Corresponding author
}

\section{To cite this article:}

Shiferaw Megersa Gemechu, Getu Segni Tulu. Safety Effects of Geometric Design Consistency on Two-lane Rural Highways: The Case of Ethiopia. American Journal of Traffic and Transportation Engineering. Vol. 6, No. 4, 2021, pp. 107-115. doi: 10.11648/j.ajtte.20210604.11

Received: June 1, 2021; Accepted: July 12, 2021; Published: July 21, 2021

\begin{abstract}
Different studies conducted, regarding the development of statistical models used to predict crash occurrences along two-lane rural highways, around the globe and particularly in Ethiopia, rely on geometric characteristics than explicitly considering measures of design consistencies. Recently, the issue of geometric design consistency in highway design is emerging as an important criterion. This study is therefore carried out to evaluate the design consistency on horizontal alignments using measures of design consistency and develop safety functions that exclusively include design consistency measures. Elements of all road sections considered in the study were rated as good, fair or poor design using design evaluation criteria. Poisson regression and Negative Binomial regression modeling approaches were used to assess the relationship between measures of design consistency and road safety. Using information criteria goodness-of-fit, Poisson regression model was found better fit to the data than NB regression models. Three different crash prediction models which explicitly incorporate design consistency measures were successfully developed. The models can be used to predict crashes of two-lane rural highway having similar characteristics with the road considered under this study. Finally, based on the results of this research, further detailed study on effect of highway design consistency on road safety and current design guides related to design speed selection to account for design consistency revision was recommended.
\end{abstract}

Keywords: Design Consistency, Road Safety, Count Model, Ethiopia

\section{Introduction}

Road traffic accident is becoming the leading cause of unintentional deaths and injuries globally. It has ranked the eighth leading cause of death for all age groups surpassing HIV/AIDS, tuberculosis and diarrheal diseases. According to the report by WHO [1], the number of annual road traffic deaths, Globally, has reached 1.35 million and approximately cause up to 50 million more injuries. Different countries across the world have tried different approaches to reduce road traffic deaths over the last few years. But the progress varies significantly among the countries. Road traffic death risk and income level of countries have a strong association. With rate of 27.5 deaths per 100,000 population, the risk is 3 times higher in low-income countries than in high-income countries where the average rate is 8.3 deaths per 100,000 population [1]. This shows that road traffic death is disproportionately high among low-income countries as seen from the size of their populations and number of motor vehicles point of view. The reason behind could be due to: shortcomings in road safety standards, vehicle technology and maintenance, design and implementation policies and safe transportation infrastructure.

In the case of Ethiopia, road crashes level is increasing over time with the growth in the number of vehicles, the population, the road network and the vehicle kilometers driven. The impact of crashes that occurred in the country between 2016 and 2018 shows that 14,194 fatalities, 22,647 serious injuries and 21,159 minor injuries [2]. This means, Ethiopians, die on the roads at an average of 4,732 persons per year; or approximately 13 citizens do not return home due to being victims of road traffic crashes. In other words, one person is killed on the roads every two hours.

Road traffic crashes tend to concentrate at certain road segments, indicating that road characteristics play a remarkable role in the collision occurrence besides a driver's 
error. One of the main reasons for crash occurrence concentrated at certain segment can be lack of geometric design consistency. According to the report by Lamme et al. [3], half of all collision on two-lane rural highways may be indirectly attributed to inappropriate speed adaptation, which indicates design consistency is related to road safety. It is also discussed, by different researchers, that horizontal curves along rural two-lane highways with design speed less than the desired speed exhibit operating speed inconsistency that may increase accident frequency [4]. Accident rates on horizontal curves of rural two-lane highways are 2 to 5 times the accident rates on tangents $[5,6]$.

A road with a good consistency level is the one in which its behavior and what drivers expect are very similar, so drivers will not be surprised while driving along them. On the other side, poor geometric design consistency means bad fitting comprising surprising events which are characterized by high-speed variability along different road segments and among different drivers [7, 8]. Where there is inconsistency which violates drive's expectation, the driver may use inappropriate maneuver or speed that may lead to collision.

Different researches have been conducted so far, in Ethiopia, regarding road safety issues on two-lane rural highways [9-12]. But in their studies, crash in general and/or pedestrian crash predicting models have been developed relying on geometric characteristics. Nevertheless, previous study shows that collision prediction models that explicitly consider measures of design consistency is superior over those that rely on geometric characteristics as it can identify geometrically inconsistent locations of sections of the highway and reflect the resulting effect it can have on collision occurrence more accurately [13].

The main objective of this study is to assess whether measures of design consistency, beyond their use to identify inconsistent alignments, really help to predict crash occurrences. That means, the design consistency of each section is evaluated and sections are rated as good, fair or poor design and its impact on road safety using measures of design consistency is determined. The findings of this research will help to predict crash occurrence on two-lane rural highways having nearly similar environmental conditions in the study area both for pre-construction and after construction alignments. This in turn will help in decision making to either redesign or warrant traffic warnings on a section that exhibit predicted number of crashes more than tolerable value.

This paper has six parts. The next section discusses a survey of scholarly sources on potential measures of design consistency. The third section deals with the methodology of the study and then followed by results found. In the fifth section, the discussion of the results presented and finally is the conclusion section.

\section{Literature Review}

Operating speed, vehicle stability, alignment indices and driver workload are the considered potential measures of design consistency areas $[13,14]$.

\subsection{Operating Speed}

The most common and simple measure of design consistency is operating speed which is defined as a speed selected by the driver under free flow condition, when there is no restriction by other users, and is represented by $85^{\text {th }}$ percentile speed usually denoted as $\mathrm{V}_{85}$ [15]. Speed-curvature relationship describes driver behavior in a better way than side friction-speed relationship does, as the operating speed may not always be equal to or less than the design speed as assumed in the design speed concept, especially on two-lane rural highways [4].

The difference between operating speed and design speed $\left(\mathrm{V}_{85}-\mathrm{V}_{\mathrm{d}}\right)$ is contented as a good indicator of any inconsistency at a single element of highway while the speed reduction between two successive elements, change in operating speed $\left(\Delta \mathrm{V}_{85}\right)$, identify any inconsistency experienced by the driver while traveling from tangent to horizontal curve [16].

Operating speed may exceed the design speed in the case when the design speed of the segment is less than or equal to $100 \mathrm{Km} / \mathrm{h}$ [4]. According to their study, relationships between design speed, operating speed, and posted speed on two-lane rural highways was found that $\mathrm{V}_{85}$ on horizontal curves was less than $V_{d}$ for all curves with $V_{d}>70 \mathrm{~km} / \mathrm{h}$ and $\mathrm{V}_{85}$ is greater than $\mathrm{V}_{\mathrm{d}}$ for most curves with $\mathrm{V}_{\mathrm{d}}<70 \mathrm{~km} / \mathrm{h}$. It was concluded that when operating speed is higher than design speed, a speed inconsistency condition will arise at such location of the case.

Using operating speed profile, reduction in operating speed between two successive elements of the road, as a measure of geometric design consistency is the most visible and effective indicator of inconsistencies since drivers reduce their operating speed when design of roads violates their driving expectancy. Operating speed on tangents connecting horizontal curves of an alignment is therefore important for design consistency evaluation. A tangent defined as an independent tangent is the one that is long enough to allow drivers to reach their desired operating speed, and consequently a speed reduction of greater than $20 \mathrm{~km} / \mathrm{h}$ is required when they enter the following horizontal curve [17].

The simplest and most common method to evaluate design consistency on successive elements is based on operating speed values as indicated in the study made by Lamm et al. [18]. Different combinations of successive elements have been studied; long tangent followed by a horizontal curve and two successive horizontal curves with or without a short tangent.

\subsection{Vehicle Stability}

Vehicle stability has been determined as an important measure of design consistency. The provision of insufficient side friction at a horizontal curve may results in skid out and rollover of a vehicle or a head-on collision of vehicles. Vehicle stability is not always guaranteed as it is inaccurately 
defined in geometric design. The mathematical representation of current geometric design standards in which the centrifugal force is balanced by the side friction between the vehicle's tires and the pavement and the weight component resulting from the super elevation is according to the following model (Ethiopian Roads Authority, 2013):

$$
r=\frac{V^{2}}{127\left(e+f_{s}\right)}
$$

Where $r=$ minimum horizontal curve radius $(\mathrm{m}), \mathrm{V}=$ design speed $(\mathrm{km} / \mathrm{h}), f_{s}=$ side friction factor and $\mathrm{e}=$ maximum super elevation rate $(\% 100)$.

But this formula is subjected to a number of criticisms because of the following facts: First, the vehicle is represented by a single mass, which ignores the interaction between side and longitudinal friction as well as the distribution of friction on the vehicle's tire. Second, the assumption that the vehicles will travel at a constant speed when negotiating a curve is not fair valid [33]. The fact is, the choice of speed is found to be compromise of the drive's desired speed and his/her acceptable level of lateral acceleration. Third, the assumption that drivers will follow a path with radius identical to the curve radius is also found invalid by empirical data. Fastest drivers accept side friction demanded which is in excess to the comfort limit [19]. Therefore, because of the above, vehicle stability may not be guaranteed regardless of a design made according to the standard.

The values of side friction demand $f_{R d}$ is calculated for each curve using the [AASHTO formula] which is presented below:

$$
f_{R d}=\frac{V_{85}^{2}}{127 r}-e
$$

Where $f_{R d}=$ side friction demand and $\mathrm{V}_{85}=$ observed operating speed $(\mathrm{km} / \mathrm{h})$.

Table 1. Design Consistency Evaluation Criteria [17].

\begin{tabular}{llll}
\hline Consistency Rating & Criteria I & Criteria II & Criteria III \\
\hline Good & $\left|V_{85}-V_{d}\right| \leq 10 \mathrm{~km} / \mathrm{h}$ & $\Delta V_{85} \leq 10 \mathrm{~km} / \mathrm{h}$ & $0.01 \leq \Delta f_{R} \leq 10$ \\
Fair & $10<\left|V_{85}-V_{d}\right| \leq 20 \mathrm{~km} / \mathrm{h}$ & $10<\Delta V_{85} \leq 20 \mathrm{~km} / \mathrm{h}$ & $-0.04 \leq \Delta f_{R}<0.01$ \\
Poor & $\left|V_{85}-V_{d}\right|>20 \mathrm{~km} / \mathrm{h}$ & $\Delta V_{85}>20 \mathrm{~km} / \mathrm{h}$ & $\Delta f_{R}<-0.04$ \\
\hline
\end{tabular}

\section{Methodology}

\subsection{Data Description}

The data used in this research are geometric design parameters, traffic volume, spot speed and crashes recorded on a two-lane rural highway located in the Oromia regional state along Addis Ababa to Gohatsion which stretches for 177 $\mathrm{Km}$. Of this two-lane rural highway, which had not undergone any modification during the period (2016-2018), has been selected for this study. It is one of the highest standard rural two-lane highway functional class in the country which joins Addis Ababa- Debre Markos- Metema Cities. According to ERA (Ethiopian Road Authority) functional classification, this road is categorized under trunk roads.

The data are generally categorized into two categories: the horizontal curves only data and the horizontal curves and tangents combined. There are 145 curves in the first category and 145 curves and 198 tangents in the second category. None of them presented curves with a radius lower than $52 \mathrm{~m}$ and larger than $850 \mathrm{~m}$. The longitudinal grades on all the road for all sections are lower than $5 \%$. Also, none of the selected road segments presented important intersections and stop-controlled that could dramatically vary their traffic volume or their operating speed. The minimum tangent length is $200 \mathrm{~m}$ on flat terrain prior to the first curve and all sections are of good pavement condition. The geometric design data were extracted from as-built drawing provided by Ethiopian Road Authority. The traffic volume data for these road segments for 3 years (2016-2018) were downloaded from the official website of the Ethiopian Road Authority.

The primary data used in this research is spot speed which is used to determine operating speeds. Locations for speed data collection were limited to the center of the horizontal curve and the midpoint of its preceding tangent. The speed data, from which operating speed $\left(\mathrm{V}_{85}\right)$ were determined, was estimated using a handheld GPS device. 50 spot speed observations at each site, the center of 145 horizontal curves and mid of 198 tangents, in each direction was collected as it would be adequate to estimate the operating speed at each location suggested by Hashim and Bird [20]. The collection of speed data was made only in daylight hours on a dry pavement. All the selected sites were not near any junctions or towns. The speed data were collected for five types of vehicle, namely: Small cars, Pickups, Minibuses (12 seats), Small buses (12-25 seats) and Medium Buses (25-45 seats) under free flow conditions. Speeds of vehicles with headway less than 5 seconds were rejected based on the assumption by Poe et al. [15] that the case of free-flow conditions would occur when the headways are equal to or greater than 5 seconds.

Crash data were provided by the traffic police office of respective district, which consisted of a list of all reported crashes during the 3 years (2016-2018) characterized by their location, date and time, daylight conditions, crash severity, vehicle type, driver characteristics, external factors, causes of the accidents, and other conditions compiled in word document. Considering all the data, a filtering process was performed. All accidents that are due animal crossing and took place during years not considered in this study were rejected. Although the most frequent consistency related type 
of accident is run-off-the road accidents [16], all accident types were considered in order to not bias the results.

Table 2. Summary Statistics of Data Used to Determine Measures of Geometric Design Consistency.

\begin{tabular}{|c|c|c|c|c|c|}
\hline Variable & Observation & Mean & Sta. Dev. & Min & Max \\
\hline \multicolumn{6}{|l|}{ Horizontal Curves Data Only } \\
\hline Design Speed & 145 & 84.48 & 11.47 & 70.00 & 120.00 \\
\hline Operating Speed & 145 & 103.24 & 11.18 & 64.13 & 116.85 \\
\hline Section Length (Km) & 145 & 0.98 & 0.52 & 0.10 & 2.19 \\
\hline Radius (m) & 145 & 306.97 & 207.44 & 52.00 & 850.00 \\
\hline Super Elevation & 145 & 4.99 & 1.43 & 2.19 & 7.81 \\
\hline Side Friction Assumed & 145 & 0.14 & 0.01 & 0.10 & 0.14 \\
\hline AADT & 145 & 3192.47 & 610.07 & 2050.00 & 3516.00 \\
\hline Crash Frequency per 3 years & 145 & 5.30 & 3.19 & 0 & 13 \\
\hline \multicolumn{6}{|c|}{ Horizontal Curves and Tangents Data Combined } \\
\hline $\mathrm{V}_{85}$ on Horizontal Curve & 198 & 104.05 & 10.84 & 64.13 & 116.85 \\
\hline $\mathrm{V}_{85}$ on Tangent & 198 & 121.01 & 5.32 & 113.30 & 133.21 \\
\hline Section Length (Km) & 198 & 0.540 & 0.515 & 0.223 & 4.355 \\
\hline AADT & 198 & 3153.20 & 634.25 & 2050.00 & 3.00 \\
\hline
\end{tabular}

\subsection{Methods}

In this study, the methodologies used in determining the effect of geometric design consistency on road safety were Poisson regression and NB regression models. Poisson regression approaches for determining the relationship between collision frequency and risk factors have been proposed [21-25]. The limitation of Poisson regression is that it assumes equality of mean and variance and as a result not suitable for considerably over dispersed data. Poisson regression models are estimated by specifying the Poisson parameter $\lambda_{i t}$ as a function of explanatory variables as given below

$\lambda_{i t}=e^{\left(\beta X_{i t}\right)}$ Where: $\lambda_{i t}$ is mean crash at the $i^{\text {th }}$ section and $t^{\text {th }}$ time of period, $X_{i t}$ is vector of explanatory variables and $\beta$ is vector of regression parameter.

To overcome the problem of over-dispersion, researchers began to use the Negative Binomial (NB) distribution (also called the Poisson-Gamma) instead of the Poisson distribution modeling [21, 26-28]. The Negative Binomial distribution uses a Gamma probability distribution and can relax the assumption of the mean equals the variance. Hence, the NB can accommodate over-dispersion that may exist in the crash data counts [29]. Negative Binomial Regression model can be obtained from the Poisson regression by adding an error term to its expected number of crashes, and becomes [30]:

$$
\lambda_{i t}=e^{\left(\beta X_{i t}+\varepsilon_{i t}\right)}
$$

with variance $\operatorname{VAR}\left(n_{i}\right)=E\left(n_{i}\right)\left(1+\alpha E\left(n_{i}\right)\right.$

Where: $e^{\left(\varepsilon_{i t}\right)}$ is a gamma-distributed error with mean equals one and variance equals $\alpha$ for all $i$ and $t, X_{i t}$ is vector of explanatory variables, $\beta$ is a vector of regression parameter and $\lambda_{i t}$ is mean crash at the $i^{\text {th }}$ section and $t^{t h}$ time of period.

Variance $\operatorname{VAR}\left(n_{i}\right)$ is different from mean, $E\left(n_{i}\right)$ for $\alpha \neq$ 0 . The error term is called the overdispersion parameter, and both $\alpha$ and $\beta$ can be estimated from the maximum likelihood function. If the parameter $\alpha$ is zero, then the model becomes
Poisson regression. But if $\alpha$ is found significantly different from zero, especially the case when the variance is significantly larger than the mean ( $\alpha$ is greater than zero), NB regression can be used instead of Poisson regression to handle the over dispersion in the data. In the case when $\alpha$ is less than zero, the data is under-dispersion. NB model has limitation of handling such case of under-dispersion data count, when the mean of the crash counts is higher than the variance [31, 32].

Goodness-of-fit: Akaike information criterion (AIC) and Bayesian information criterion (BIC) were used for assessing the fitness of the regression model to the observed data between Poisson and NB regression models.

\section{Variable Selection for Model Development}

The selection of explanatory variables should be supported by previously documented crash frequency evidence available from research literature. Nevertheless, in practice it is often dictated simply by data at hand. Based on the availability of data the explanatory variables considered in this study are described as follows.

Exposure terms: Exposure variables can be resented by two different terms: traffic volume (AADT) and section length $(\mathrm{L})$ or as a single term is million vehicles in a unit length of one kilometer (MVK). The selection of exposure term to include in the model was done following three approaches. These were by examining: the transformed values of AADT and section length separately; the transformed form of a single exposure term (MVK); the untransformed values of AADT and section length. To come up with most appropriate selection in this study, Poisson and Negative Binomial regression models were done for each. As a result, transformed single exposure term (MVK) was found appropriate.

Other explanatory variables: Other explanatory variables included in the study were design consistency measures. Three design consistency measures, based on availability of data, were used to determine the safety benefit of design consistency. These are design speed consistency $\left(\left|\mathrm{V}_{85}-\mathrm{V}_{\mathrm{d}}\right|\right)$, operating speed consistency $\left(\Delta \mathrm{V}_{85}\right)$ and consistency in 
driving dynamics $\left(\Delta f_{R}\right)$.

The decision to include a variable in the model was following the criteria described below:

1) Sign of estimates was instinctively associated with crash frequency prediction model relying on previous research evidence.

2) P-Value for each estimate of the variable needed to be significant at $10 \%$ level.

3) Each included variable has to have minimal correlation with other independent variables.

In doing so, each variable and or in pair were examined together with the exposure term (MVK) using Poison and Negative Binomial regression. The result showed that the inclusion of more than one independent variable (measure of design consistency) with a single exposure term to a single model was failed with one of the above criteria to reasonably fit with the data. On the other hand, each design consistency measure together with exposure term was found statistically significant. As a result, three models have been developed that incorporate only one design consistency measure.

Table 3. Statistical Summary of Design of Consistency Measures Used to Evaluate the Existing Alignment and Model Development.

\begin{tabular}{lccccc}
\hline Variable & Observation & Mean & Sta. Dev. & Min. & Max. \\
\hline Horizontal Curves Data Only & & & & & \\
$\mathrm{V}_{85}-\mathrm{V}_{\mathrm{d}}$ & 145 & 20.27 & 11.466 & 1.027 & 46.852 \\
$\Delta f_{R}$ & 145 & 0.00447 & 0.0692 & -0.111 & 0.1334 \\
Horizontal Curves and Tangents Data Combined & 198 & 16.975 & 10.509 & 0.219 & 53.628 \\
$\mathrm{~V}_{85 \mathrm{~T}}-\mathrm{V}_{85}$ & 198 & & \\
\hline
\end{tabular}

Note: $\mathrm{V}_{85}=$ Operating speed of horizontal curve; $\mathrm{V}_{\mathrm{d}}=$ Design speed of Horizontal curve; $\mathrm{V}_{85 \mathrm{~T}}=$ Operating speed of preceding tangent to a horizontal curve; $\Delta f_{R}=$ Side friction assumed minus side friction demanded.

\section{Result}

\subsection{Evaluation of Existing Alignment}

Three types of design consistency measures were used to rate the existing alignment of each section as good, fair and poor design using the criteria I, II and III (given in Table 1). These measures are: reduction in operating speed between successive sections ( $\Delta V_{85}$ ), absolute difference between operating speed and design speed $\left(\left|V_{85}-V_{d}\right|\right)$ and the difference between side fiction assumed and demanded $\left(\Delta f_{R}\right)$. The evaluation result, using each criterion and corresponding measure of design consistency, is provided in Figures 1, 2 and 3.

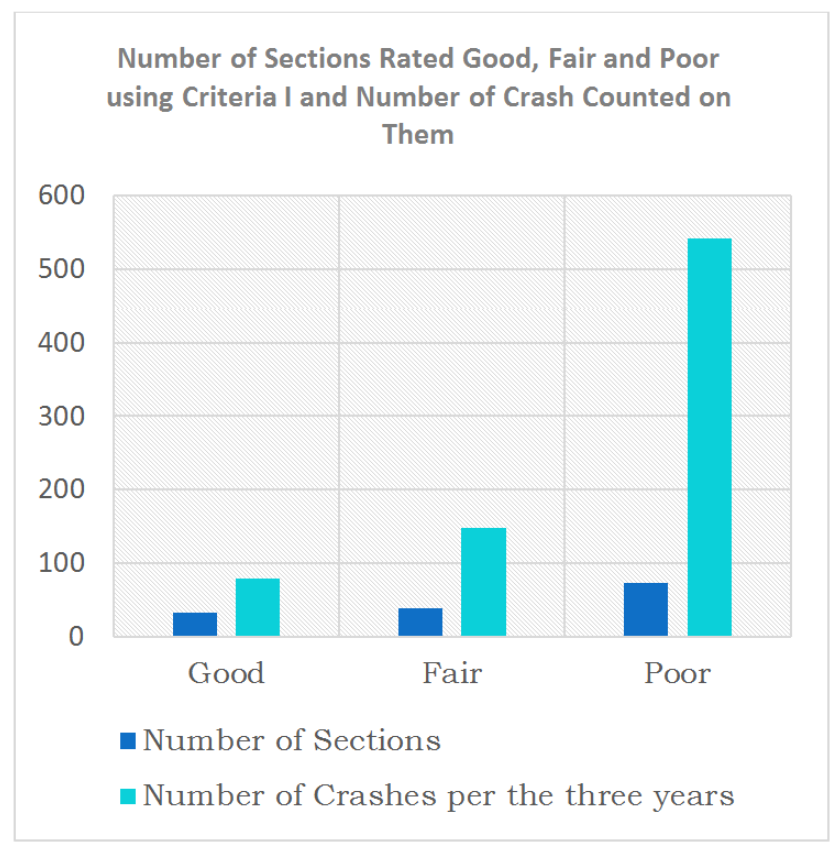

Figure 1. Number of Crashes and Sections Rated using Criteria I.

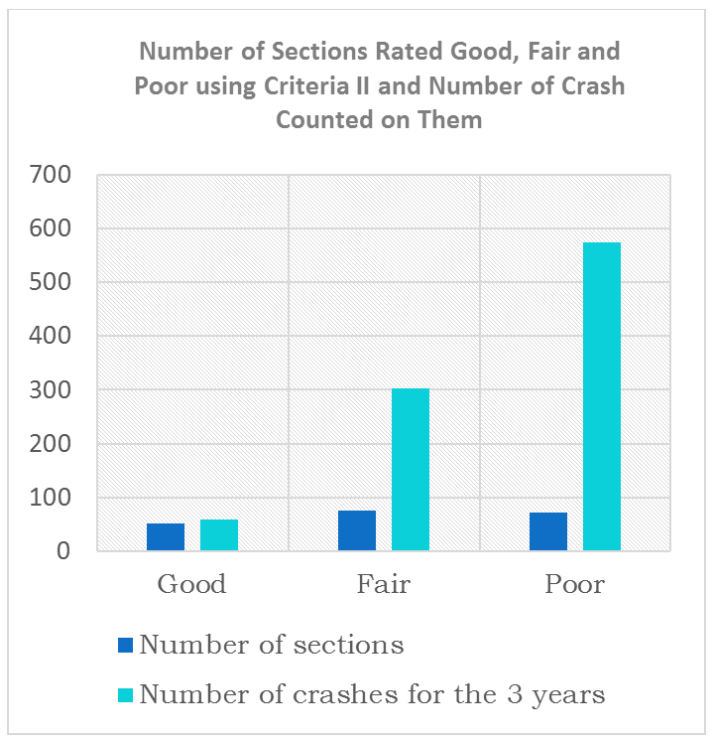

Figure 2. Number of Crashes and Sections Rated using Criteria II.

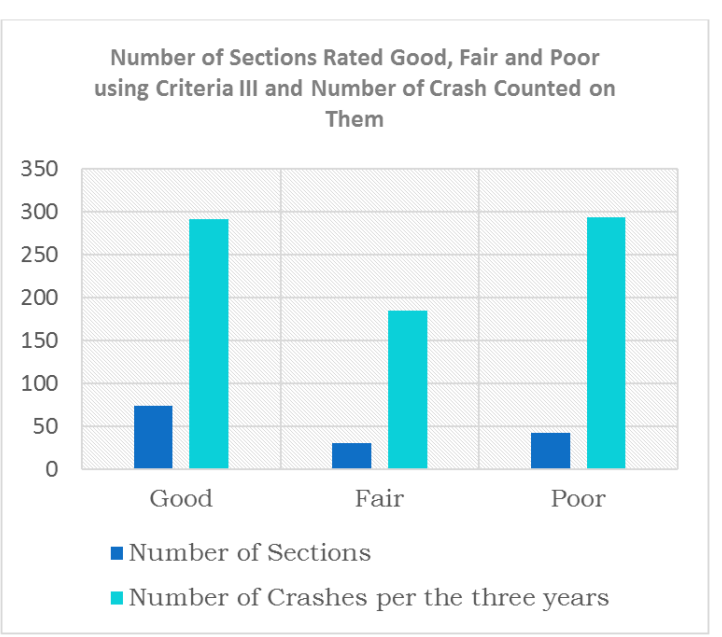

Figure 3. Number of Crashes and Sections Rated using Criteria III. 


\subsection{Modeling Results}

\subsubsection{Models Developed Using Horizontal Curves Data Only}

Table 4. Poisson and NB Regression Model Results Using Horizontal Curve Only.

\begin{tabular}{|c|c|c|c|c|c|c|c|c|c|c|c|c|}
\hline \multirow{2}{*}{ Variables } & \multicolumn{6}{|c|}{ Poisson Regression } & \multicolumn{6}{|c|}{ NB Regression } \\
\hline & Estimate & Std. Err. & $\mathbf{Z}$ & Prob. & $\mathbf{z}$ & $>\mathbf{Z}$ & Estimate & Std. Err. & $\mathbf{z}$ & Prob. & $\mathbf{z}$ & $>\mathbf{Z}$ \\
\hline \multicolumn{13}{|c|}{ Models 1 (Using absolute difference between operating speed and design speed) } \\
\hline Constant Term & $2.4547 * * *$ & 0.7625 & 3.22 & 0.001 & & & $2.4589 * * *$ & 0.7541 & 3.41 & 0.001 & & \\
\hline $\log (\mathrm{MVK})$ & $0.2686^{* *}$ & 0.1138 & 2.36 & 0.018 & & & $0.1187 * *$ & 0.1831 & 2.54 & 0.018 & & \\
\hline$\left|V_{85}-V_{d}\right|$ & $0.0335 * * *$ & 0.0052 & 6.44 & 0.000 & & & $0.0115 * * *$ & 0.0422 & 6.81 & 0.000 & & \\
\hline Log likelihood at convergence & -277.1895 & & & & & & -277.1918 & & & & & \\
\hline Chi squared (2) & 206.77 & & & & & & 169.87 & & & & & \\
\hline $\mathrm{AIC}$ & 560.38 & & & & & & 562.38 & & & & & \\
\hline $\mathrm{BIC}$ & 570.25 & & & & & & 575.54 & & & & & \\
\hline \multicolumn{13}{|c|}{ Model 2 (Using difference between side friction assumed and side friction demanded) } \\
\hline Constant Term & $6.1772 * * *$ & 0.4558 & 13.55 & 0.000 & & & $6.4272 * * *$ & 0.4772 & 14.01 & 0.000 & & \\
\hline $\log (\mathrm{MVK})$ & $0.7754 * * *$ & 0.07907 & 9.81 & 0.000 & & & $0.3724 * * *$ & 0.0791 & 9.88 & 0.000 & & \\
\hline$\Delta \mathrm{f}_{\mathrm{R}}$ & $-1.4415^{* *}$ & 0.6036 & -2.39 & 0.017 & & & $-1.5215^{* *}$ & 0.7126 & -2.40 & 0.017 & & \\
\hline Log likelihood at convergence & -293.24 & & & & & & -293.6244 & & & & & \\
\hline Pseudo $\mathrm{R}^{2}$ & 0.2285 & & & & & & 0.1892 & & & & & \\
\hline AIC & 593.25 & & & & & & 595.25 & & & & & \\
\hline $\mathrm{BIC}$ & 603.18 & & & & & & 607.16 & & & & & \\
\hline
\end{tabular}

Note: $* * *, * * *$ significance at $1 \%, 5 \%, 10 \%$ level respectively

For this set of data two measures of design consistency were used as independent variables. These are $\left(\left|\mathrm{V}_{85}-\mathrm{V}_{\mathrm{d}}\right|\right)$ and $\left(\Delta f_{R}=f_{R a}-f_{R d}\right)$. There have been two distinct models developed for this set of data each including only one of the design consistency measure in addition to the exposure term using Poisson and NB regression as provided in Table 4.

\subsubsection{Model Developed Using Horizontal Curves and Tangents Data Combined}

For this set of data only one design consistency measure, $\Delta \mathrm{V}_{85}$, was selected to develop the model along with exposure term using Poisson and NB regression as given Table 5.

Table 5. Poisson and NB Regression Model Results for Crash Frequency Using Horizontal Curves and Tangents Data Combined.

\begin{tabular}{|c|c|c|c|c|c|c|c|c|c|c|c|c|}
\hline \multirow{2}{*}{ Variables } & \multicolumn{6}{|c|}{ Poisson Regression } & \multicolumn{6}{|c|}{ NB Regression } \\
\hline & Estimate & Std. Err. & $\mathbf{Z}$ & Prob. & $\mathbf{z}$ & $>\mathbf{Z}$ & Estimate & Std. Err. & $\mathbf{z}$ & Prob. & $\mathbf{z}$ & $>\mathbf{Z}$ \\
\hline \multicolumn{13}{|c|}{ Model 3 (Using difference between operating speeds on successive elements) } \\
\hline Constant Term & $1.5078 * * *$ & 0.4208 & 3.58 & 0.000 & & & $1.2412 * * *$ & 0.4579 & 3.52 & 0.000 & & \\
\hline $\log (\mathrm{MVK})$ & $0.1503 * *$ & 0.0633 & 2.38 & 0.018 & & & $0.1205 * *$ & 0.0822 & 2.41 & 0.018 & & \\
\hline$\Delta \mathrm{V}_{85}$ & $0.0508 * * *$ & 0.0025 & 20.41 & 0.000 & & & $0.0211 * * *$ & 0.2121 & 20.41 & 0.000 & & \\
\hline Log likelihood at convergence & -392.918 & & & & & & -392.988 & & & & & \\
\hline Chi squared (2) & 373.84 & & & & & & 231.53 & & & & & \\
\hline Pseudo $\mathrm{R}^{2}$ & 0.3224 & & & & & & 0.2275 & & & & & \\
\hline $\mathrm{AIC}$ & 792.97 & & & & & & 793.98 & & & & & \\
\hline $\mathrm{BIC}$ & 801.84 & & & & & & 807.13 & & & & & \\
\hline
\end{tabular}

Note: $* * *, * * *$ significance at $1 \%, 5 \%, 10 \%$ level respectively

\section{Discussion}

From the result of existing alignment evaluation, it can be observed from simple categorical presentation provided in Figures 1 and 2 the number of crashes counted were large on total sections rated fair and even larger on those rated poor design as compared to that counted on good design sections. This indicates that design consistency has significant impact on road safety.

The possible reasons for drivers chose of speed that is greater than the design speed could be one or any combination of the following.

i. Drivers' behavior: the choice of operating speed is highly dependent on the experience of the drivers. Familiar derivers usually have tendencies of choosing higher operating speed than unfamiliar ones regardless of similarity of other constraints.

ii. The design speed selection: design speed concept is the basis for all geometric design guidelines. According to the national design speed concept of Ethiopia, it is determined based on road type and terrain category which is used to select key elements of geometric design among which the most important one is the determination of minimum radius of horizontal curve. The minimum radius of horizontal curve is determined using the assumed design speed and maximum 
permissible super elevation to guarantee safe driving speed on curves. This way determining the minimum radius, without having an upper limit curve radius, allows designers to take any curve radius above the minimum value. As it is clear that on flatter curves driving speeds are higher than on curves with small radii. Thus, alignments designed based on the design speed concept this way may generate operating speeds that deviate considerably from design speed.

On the other hand, the possible reasons for the large speed difference between successive road elements could be the effects of successive roadway features on drivers. On curves with small radii usually drivers tend to choose small operating speed while large speed on long tangent sections. Thus, long tangent section followed by a curve with small radius will introduce large difference between operating speed on horizontal curve and its preceding tangent section.

The result of existing alignment evaluation presented in Table 3 shows that the ratio between crash frequency and number of sections in each category of rating (as good, fair or poor) is found to be $3.99,6.13$ and 6.98 respectively. This indicates that crash frequency is inversely proportional with design consistency. The possible reasons for this could be besides rough assumptions in the equation from which side friction assumed is determined there are some factors like: derivers behavior, horizontal curve length and radii, adjacent road geometry and environmental effects. Fastest drivers accept side friction demanded which is in excess to the comfort limit. Therefore, because of the above, vehicle stability may not be guaranteed regardless of a design made according to the standard.

The AIC and BIC values for Poisson model were less than that was for Negative Binomial model for all models (Table 4 $\& 5$ ), indicating that the models developed by Poisson better fit with the data. The exposure term Log (MVK) was statistically significant at 5\% level for all models and positively associated with crash frequency as expected.

In model 1, the absolute difference between operating speed and design speed of horizontal curve $\left(\left|\mathrm{V}_{85}-\mathrm{V}_{\mathrm{d}}\right|\right)$ effects was highly significant at $1 \%$ level and the direction of relationship indicates that the greater the $\left(\left|\mathrm{V}_{85}-\mathrm{V}_{\mathrm{d}}\right|\right)$ experienced by drivers on a horizontal curve, the greater the curve's crash occurrence. A similar study done by $\mathrm{Ng}$ and Sayed [13] found also a positive correlation between ( $\mid \mathrm{V}_{85}$ $\mathrm{V}_{\mathrm{d}} \mid$ ) and crash frequency.

In the case of model 2 , the change inside friction $\left(\Delta f_{R}\right)$ was significant at a level $5 \%$. Its direction of correlation indicates that the greater the difference between side friction assumed and side friction demand the fewer the crashes are expected to occur on horizontal curve. This negative direction relationship found for $\Delta f_{R}$ is the same result with result similar studies conducted by $\mathrm{Ng}$ and Sayed, [27].

Lastly, in model 3 , reduction in operating speed $\left(\Delta \mathrm{V}_{85}\right)$ was found highly significant at $1 \%$ level and positively associated with crash frequency at the horizontal curve. From the direction of a relationship, it means, the greater the change in operating speed at horizontal curve the greater the crash frequency expected to occur. The significance and direction of association for this variable was found to be the same with similar studies conducted $[13,33]$.

Thus, the findings support the use of three design consistency measures: absolute difference between operating speed and design speed, difference between side friction assumed and side friction demand, and reduction in operating speed to identify inconsistent sections and predict safety impacts of two-lane rural highway.

\section{Conclusion}

Based on evaluation of existing alignments it has been observed that the more geometrically inconsistent the alignment, the greater number of crashes would be occurred, as it was expected. Therefore, making any change to the alignment so that avoidance or reduction of sections rated as geometrically fair and poor design would bring in the reduction of number of crash occurrence to high degree. Hence, for fair rated sections, where geometrically minor inconsistencies have been observed, traffic warnings could be possibly warranted to limit drivers operating speed so that operating speed inconsistency for successive elements and design speed inconsistency for single element could be resolved. For sections rated poor, where geometrically strong inconsistencies have been observed, redesign of alignment has to be considered.

Three different models that incorporate individual measure of design consistency and could be used to predict crash frequency on two-lane rural highway segment having nearly similar environmental factors to the segment considered in this study have been successfully developed. The models developed in this study depend on the design consistency measures used and are limited to horizontal curves and tangents only. This may limit the applicability of the developed models to sections that are combined with vertical curves. Two of the design consistency measures are based on operating speed profiles which has been estimated by the researcher as operating speed predicting model is not yet developed in the country. Therefore, future research works to be conducted on the study of effect of geometric design consistency of two-lane rural highways and road safety should be devoted on: establishing new methodologies to evaluate design consistency of alignments considering the effect of 3D sight distance; developing models used to predict operating speed; studying the effect of design consistency on highway capacity and level of service; and revising current design guides, selection of design speed, to account for design consistency.

\section{References}

[1] World Health Organization. Global Status Report on Road Safety (2018). World Health Organization: Geneva, Switzerland, 2018. 
[2] Federal Police Commission (2019). Annual crash data report. Addis Ababa.

[3] Lamm, R., Hayward, J., and Cargin, J. (1986). Comparison of different procedures for evaluating speed consistency. Transportation Research Record: Journal of Transportation Research Board, No. 1100, 10-19.

[4] Fitzpatrick, K., Krammes, R. A., and Fambro, D. B. (1997). Design Speed, Operating Speed, and Posted Speed Relationship. Institution of Transportation Engineers Journal, Vol. 67, No. 2, p. 52-59.

[5] A policy on geometric design of highways and streets. (2018). American Association of State Highway and Transportation Officials (AASHTO), $7^{\text {th }}$ edition, Washington, D.C.

[6] Krammes, R. A. (2000). Design Speed and Operating Speed in Rural Highway Alignment Design. Transport Research Record 1701, National Research Council, Washington, D.C., pp. $68-75$.

[7] Fitzpatrick, K., Wooldridge, M. D., Tsimhoni, O., Collins, J. N., Green, P., Bauer, K. M., Parma, K. D., Koppa, R., Harwood, D. W., Anderson, I., Krammes, R. A., and Poggioli, B. (2000). Alternative Design Consistency Rating Methods for Two-Lane Rural Highways. Report FHWA-RD-99-172. RHWA, U.S. Department of Transportation.

[8] Gibreel, G. M., Easa, S. M., Hassan, Y., and El-Dimeery, I. A. 1999. State of the art of highway geometric design consistency. ASCE Journal of Transportation Engineering, 125 (4): 305-313.

[9] Abebe, Mandefro Terefe, and Moltot Zewdie Belayneh. 2018. "Identifying and Ranking Dangerous Road Segments a Case of Hawassa-Shashemene-Bulbula Two-Lane Two-Way Rural Highway, Ethiopia." Journal of Transportation Technologies 08 (03): 151-74.

[10] Mulugeta Tola, Alamirew, and Alemayehu Gebissa. 2019. "Assessment on the Impacts of Road Geometry and Route Selection on Road Safety: A Case of Mettu-Gore Road, Ethiopia." American Journal of Civil Engineering and Architecture 7 (1): 13-19.

[11] Munea, S. A., Raju, Ramesh Reddy, and Gebrefilmuna Abera. 2020. "Evaluating the Impact of Various Geometric Characteristics of Rural Two Lane Road on Traffic Safety in Ethiopia." International Journal of Civil Engineering 7 (6): $1-11$.

[12] Tulu, G. S., Washington, S., Haque, M. M., and King, M. J. (2015). "Investigation of Pedestrian Crashes on Two-Way Two-Lane Rural Roads in Ethiopia." Accident Analysis and Prevention 78: 118-26.

[13] Ng, J. C. W., Sayed, T. (2004). Effect of geometric design consistency on roads safety. Canadian Journal of Civil Engineering 31 (2), 218.

[14] Awata, M., Hassan, Y. (2002). Towards establishing an overall safety-based geometric design consistency measure. In: 4th Transportation Specialty Conference of the Canadian Society for Civil Engineering.

[15] Poe, C. M., Tarris, J. P., and Mason, J. M., Jr. (1996). Relationship of operating speed to roadway geometric design speed. Report FHWA-RD-96-024. Federal Highway Administration, U.S. Department of Transportation, Washington, D.C.
[16] Camacho-Torregrosa, Francisco J., Ana M. Pérez-Zuriaga, J. Manuel Campoy-Ungría, and Alfredo García-García. "New geometric design consistency model based on operating speed profiles for road safety evaluation", Accident Analysis \& Prevention, 2012.

[17] Lamm, R., Psarianos, B., and Mailaender, T. (1999). Highway design and traffic safety engineering handbook. McGraw-Hill Companies, Inc., New York, N. Y.

[18] Lamm, R., Choueiri, E. M., and Hayward, J. C. (1988a). Tangent as an independent design element. Transportation Research Record 1195, Transportation Research Board, Washington, D.C., 123-131.

[19] Chowdbury, M A., Warren, D. L., and Bissell, H. (1991). Analysis of Advisory Speed Setting Criteria, public Roads, Vol. 55, No. 3, p. 65-71.

[20] Hashim I H and Bird R N (2005). Operating Speed Behaviour Models for Single Rural Carriageways-Case Study of North East of England, Proceedings of the 37th Annual Conference, Universities' Transport Study Group, University of Bristol, Bristol.

[21] Abdulhafedh, A. (2016). Crash Frequency Analysis. Journal of Transportation Technologies, 6, 169-180.

[22] Blincoe, J., Miller, R., Zaloshnja, E. and Lawrence, A. (2015). The Economic and Societal Impact of Motor Vehicle Crashes, 2010. National Highway Traffic, Washington DC.

[23] Lord, D. and Bonneson, A. (2007). Development of Accident Modification Factors for Rural Frontage Road Segments in Texas. Transportation Research Record, 2023, 20-27.

[24] Ma, J., Kockelman, K. M. and Damien, P. (2008). A Multivariate Poisson-Lognormal Regression Model for Prediction of Crash Counts by Severity, Using Bayesian Methods. Accident Analysis and Prevention, 40, 964-975.

[25] Park, S. and Lord, D. (2007). Multivariate Poisson-Lognormal Models for Jointly Modeling Crash Frequency by Severity. Transportation Research Record, 2019, 1-6. https://doi.org/10.3141/2019-01

[26] Daniels, S., Brijs, T., Nuyts, E. and Wets, G. (2010). Explaining Variation in Safety Performance of Roundabouts. Accident Analysis and Prevention, 42, 292-402.

[27] Geedipally, R., Lord, D. and Dhavala, S. (2012). The Negative-Binomial Lindley Generalized Linear Model: Characteristics and Application Using Crash Data. Accident Analysis and Prevention, 45, 258-265.

[28] Malyshkina, N. and Mannering, F. (2010). Markov Switching Multinomial Logit Model: An Application to Accident-Injury Severities. Accident Analysis and Prevention, 41, 829-838.

[29] Hilbe, J. (2014) Modeling Count Data. Cambridge University Press, London. https://doi.org/10.1017/CBO9781139236065

[30] Lord, D., and Mannering, F. (2010). The Statistical Analysis of Crash Frequency Data: A Review and Assessment of Methodological Alternatives. Accident Analysis and Prevention, 44, 291-305.

[31] Amoros, E., Martin, J. L., \& Laumon, B. (2003). Comparison of Road Crash Incidents and Severity between Some French Counties. Accident Analysis and Prevention, 35, 537-547. https://doi.org/10.1016/S0001-4575(02)00031-3. 
[32] Oh, J., Washington, S. and Nam, D. (2006). Accident Prediction Model for Railway-Highway Interfaces. Accident Analysis and Prevention, 38, 346-356.

[33] Anderson, I. B., Bauer, K. M., Harwood, D. W., and
Fitzpatrick, K. (1999). Relationship to safety of geometric design consistency measures for rural two-lane highways. Transportation Research Record 1658, Transportation Research Board, National Research Council, Washington, D.C. p. $43-51$. 